\title{
Identification and targeted gene disruption of cAR3, a cAMP receptor subtype expressed during multicellular stages of Dictyostelium development
}

\author{
Ronald L. Johnson, ${ }^{1}$ Charles L. Saxe III, ${ }^{2,3}$ Rachel Gollop, ${ }^{2}$ Alan R. Kimmel, ${ }^{2}$ and \\ Peter N. Devreotes ${ }^{1,4}$ \\ ${ }^{1}$ Department of Biological Chemistry, Johns Hopkins University School of Medicine, Baltimore, Maryland 21205 USA; \\ ${ }^{2}$ Laboratory of Cellular and Developmental Biology, NIDDKD (6/B1-12), National Institutes of Health, \\ Bethesda, Maryland 20892 USA
}

Extracellular cAMP acts through cell-surface receptors to coordinate the developmental program of Dictyostelium. A cAMP receptor (cAR1), which is expressed during early aggregation, has been cloned and sequenced previously. We have identified a new receptor subtype, cAR3, that has $\sim 56 \%$ and $69 \%$ amino acid identity with cAR1 and cAR2, respectively. cAR1, cAR2, or cAR3 expressed from plasmid in growing Dictyostelium cells can be photoaffinity labeled with 8- $\mathrm{N}_{3}\left[{ }^{32} \mathrm{P}\right] \mathrm{cAMP}$ and phosphorylated when stimulated with CAMP. CAR3 RNA was not present during growth but appeared during late aggregation. Its expression peaked at $9 \mathrm{hr}$ and then fell to a reduced level that was maintained until culmination. The expression of cAR3 protein followed a similar pattern, but with a 3-hr lag, and reached a maximum at the mound stage. In contrast, cAR1 protein was expressed predominantly during early aggregation and at low levels during later stages. At their respective peaks of expression, there were $\sim 5 \times 10^{3}$ cAR3 sites per cell compared with $\sim 7 \times 10^{4}$ cAR1 sites per cell. The cAR3 gene was disrupted by homologous recombination in several different parental cell lines. Surprisingly, the $\operatorname{car}^{-}$cell lines display no obvious phenotype.

[Key Words: cAMP; receptors; Dictyostelium; morphogenesis]

Received August 14, 1992; revised version accepted November 30, 1992.

Extracellular cAMP, binding to cell-surface receptors, is critical to the developmental program of Dictyostelium. During early development, oscillations of cAMP move outward from organization centers in concentric or spiral waves to coordinate the aggregation of many thousands of single amoebas. cAMP acts during aggregation both as a chemoattractant and as a cell-cell signaling molecule. After $\sim 30$ oscillations, cells form a tight aggregate and differentiation begins with the formation of prestalk and prespore cell types. Development results in the formation of a fruiting body, which consists of a stalk structure that holds aloft a mass of spores (Devreotes 1982).

A cAMP receptor, cAR1, has been identified and, characteristic of G-protein-linked receptors found in yeast and vertebrates (Dohlman et al. 1991), its sequence consists of seven potential transmembrane domains and a cytoplasmic carboxyl terminus (Klein et al. 1988). Present within its carboxy-terminal region are serine res-

\footnotetext{
${ }^{3}$ Present address: Department of Anatomy and Cell Biology, Emory University School of Medicine, Atlanta, Georgia 30322 USA.

${ }^{4}$ Corresponding author.
}

idues, which are the sites of ligand-induced phosphorylation (D. Hereld, R. Vaughan, and P. Devreotes, in prep.). cAMP stimulation of intact cells causes cAR1 to shift in size from 40 to $43 \mathrm{kD}$ and to acquire $\geqslant 4$ moles of phosphate (Klein et al. 1987). The kinetics and dose dependence of CARl phosphorylation and dephosphorylation closely correlate with that of adaptation and deadaptation of several cAMP-induced responses. This regulation probably underlies the oscillatory behavior of the cells in early aggregation (Vaughan and Devreotes 1988).

Cell-surface cAMP-binding sites are present throughout development (Schaap and Spek 1984). cAR1 accounts for the sites detected during early aggregation (Klein et al. 1987), but the molecular basis of a second smaller peak measured during early culmination is unknown. The cyclic nucleotide specificity of these binding sites is similar to that of CAR 1 and affinities of cAMP binding to membranes of these cells can be inhibited by GTP $\gamma$ S, indicating that there are receptor-G protein interactions (Schaap and Van Driel 1985; Schenk et al. 1991).

Cells that lack cAR1 by gene disruption (car1- ${ }^{-}$cells) do not enter the developmental program but remain as a monolayer of single cells (Sun and Devreotes 1991). Al- 
though these cells have almost no detectable surface cAMP-binding sites, several lines of evidence suggest that another cAR is present. After prolonged periods of starvation car $1^{-}$cells are weakly responsive in assays that measure chemotaxis to cAMP. When mixed with wild-type cells, some car $1^{-}$cells can develop to form spores, albeit at a very low efficiency (Sun and Devreotes 1991). Finally, adenylyl cyclase activity is detectable in car1 $1^{-}$cells, but the kinetics and magnitude of this response differs from that attributed to cAR1 (M. Pupillo et al. 1992).

As reported in the accompanying article, cAR2 is a receptor subtype expressed in prestalk cells predominantly during slug formation (Saxe et al. 1992). Cells that lack cAR 2 by gene disruption (car2- cells) are delayed in development at the mound stage and fail to readily form tips. cAR2 appears to facilitate the continuation of morphogenesis into later development (Saxe et al., this issue). In this report we describe the identification of a third cAMP receptor subtype, cAR3, that shares $\sim 65 \%$ amino acid identity with the other members. The peak expression of cAR3 is at the mound stage, which follows cAR 1 but precedes cAR2. We demonstrate that all three receptors are photolabeled with $8-\mathrm{N}_{3}\left[{ }^{32} \mathrm{P}\right] \mathrm{CAMP}$ and undergo ligand-stimulated phosphorylation. Unlike car $1^{-}$ and car $2^{-}$cells that are blocked at different developmental stages, cells that lack cAR3 by homologous recombination do not display an overtly altered pattern of development. This phenotype suggests that cAR3 may control a subtle aspect of morphology during late aggregation, but CAR1 and cAR2 are able to compensate for its loss.

\section{Results}

\section{Isolation of the cAR3 gene}

About $10^{5}$ colonies from a partial Sau3A genomic library were screened using a full-length CAR1 CDNA as a probe (Klein et al. 1988). Of the four clones isolated, three had a restriction map corresponding to the genomic organization of the cAR1 locus, whereas the fourth clone, designated GR6, hybridized more weakly and yielded a different restriction pattern. After removal of an intron according to its consensus splice sites (see Saxe et al., this issue), the sequence contained a 1470 -bp open reading frame (ORF) encoding a putative protein of 490 amino acids. There were two in-frame AUGs at the $5^{\prime}$ end of the coding region (Fig. 1). Translational initiation probably begins at the first AUG because in-frame stop codons were $5^{\prime}$ of this location (data not shown). The ORF encoded a protein with a calculated molecular mass of 56,174 daltons.

Using GR6 as a probe, four cDNAs were obtained in a screen of $5 \times 10^{5}$ phage of a $\lambda$ gtl1 library constructed from pooled RNA isolated from 2-, 3-, and 4-hr cells (Klein et al. 1988). The cDNA sequences, which encompassed almost the entire coding region of GR6, confirmed the genomic nucleotide sequence and the placement of the intron. On the basis of its extensive homol-
AATTITITITITGAAAATAAAAAAAAAAAAAAA ATG GAA AAT ITA AAT ACA ACA AGT ACG GCA GCA TIA ACT GGT ATG ACA AAA CAA GAG AAT GAT GCA TCA TAT GCA GTT CTA TTG aTI GCA GAT TIT ACA TCA ATA ATT GGT TGT ACA TIA GIT TIA ITA GGT

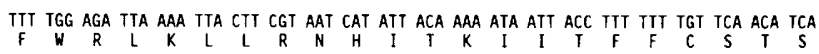
ITA GCC AAA GAT TTA ATA TCA ACA ATT TIA ACA IIG ATT GAA AAG AAA CAA TCA AAT GGG TCA TTC CAA TGT TAC CTT TAC GCA ACI GIT ATC ACT TAT GGT TCA TIG GCA TGT TGG CTT TGG ACA TTA TGT

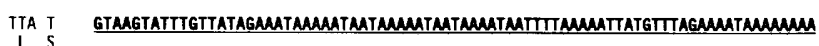

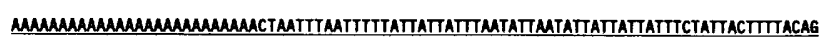

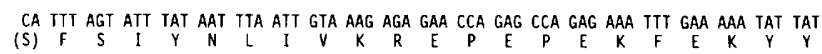
CAT GIT TIT TGT TGG GIT GTA CCA TIT ATA ATG TCA GTG ATA ATG TIG ICA AAG GGT GIT ATA GAG GTG ACG GGT AAT TGG TGT TGG ATI GGT AAC ACT TAT GTT GGG TAT AGA TIT GGC ITG ITI TAC GGA $\underset{V}{G T} T_{G}$ ACG GGT AAT TGG TGT TGG ATT GGT AAC ACT TAT GTT GGG TAT AGA TIT GGC TTG TTT TAC GGA

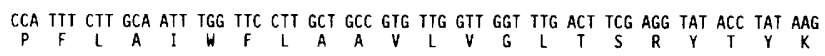

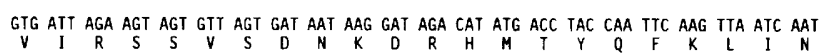
TAT ATA AIT GTT TTC CTT ITA TGT TGG GTG TTT GCT GTT ATT AAT CGT ATT GIC AAT GGC ITG AAT $Y$ I I V F L L C W V F A V I N R I V N G L N ATG IIT CCA GCT TGG GIT AGT ATT CTT CAC ACC TAT CTA AGT GTA TCG CAT GGT TTC TAT GCT TCG

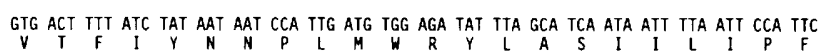
ACA AAG IIT GGT TAT TIT GIT GAA ACT CAA CAA AGA TTA GAA AAA AAT AAA AAT AAT AAT AAT CAT TCA CCA GTT GGG TTA TCA AAT AAT GCT CAA AAT AAT AAT CAT CAT CAT AAT CAT AAT AAT AAT CAC

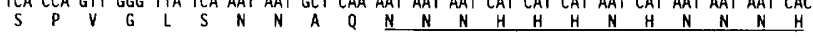
AAT AAT AAT CAT AAT AAT CAT AAT AAC AAT AAT AAT AAC AAT AAT AGT GAT IIC GTT AAT AAT GAC TCA AGT AAT TAT TAT ACT GCT TCA ATG ATT GAA TCA TTC TCT GTT CAA AAT GAA AAT TCA AAA TCT ATA AAT GGT GCT GAT AAT ITT AAA CAA AAT GGT GCA AGT CAA CAA GAT GAT AAA GAT TCT CCA AAT AGT AAT aAT aAT AAT AAT aAT AAT AAT AAT AAC AAT AAT AAT AAT AAT AAT AAT AAT AAT AAT AAT

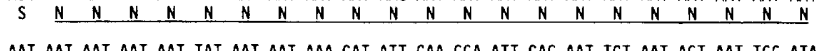
AAT AAT AAT AAT AAT TAT AAT AAT AAA GAT ATT GAA CCA ATT GAC AAT TGT AAT ACT AAT TCC ATA

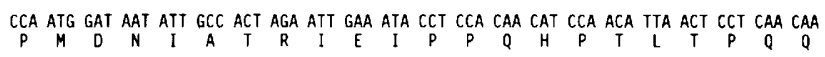
ICA TTA CAA GAA ATT AAT TTA AAT GAT GAC GAC AAC AAA ATT AAT ACT CAC CAA AGT AAC AAA AAA \begin{tabular}{llllllllllllllllllllll}
5 & $L$ & $Q$ & $E$ & 1 & $N$ & $L$ & $N$ & $D$ & $D$ & $D$ & $N$ & $K$ & $I$ & $N$ & $T$ & $H$ & $Q$ & $S$ & $N$ & $K$ & $K$ \\
\hline
\end{tabular} AAA GAT TCA AAT GIT TAAAAAAAAAAAAAAAAATCCAAGAGTTTGAAAAAAAAAAA

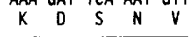

Figure 1. Sequence of cAR3. Translation of the nucleotide sequence of GR6, after removal of the intron, results in a protein of 490 residues. The intron is shown in boldface type and underlined. Strings of asparagine repeats are underlined. The epitope used to generate cAR3 antiserum is double underlined.

ogy with cAR1 and cAR2 (Saxe et al. 1992), this ORF was designated cAR3.

\section{cAR3 sequence}

The major features of the predicted cAR3 protein were similar to those of cAR1 (Klein et al. 1988). A hydropathy plot revealed six strongly hydrophobic domains, and a seventh amphipathic region that could form seven transmembrane domains of $\sim 20-25$ residues each (Kyte and Doolittle 1982). The final 220 residues of the protein, $\sim 45 \%$ of the sequence, are primarily hydrophilic. This topology is characteristic of the superfamily of G-protein-coupled receptors, such as the adrenergic receptors 
(O'Dowd et al. 1989) and the rhodopsins (Findlay and Pappin 1986; Hargrave 1986). Similar to the proposed structure of these receptors, cAR3 would have an extracellular amino terminus and a long cytoplasmic carboxyl terminus.

The extracellular portions of cAR3 contain two potential amino-linked glycosylation sites (Asn- $X$-Ser/Thr; Hubbard and Ivatt 1981). One site is located at asparagine 5 near the amino terminus and the other at asparagine 204 in the loop between the second and third putative transmembrane domains (Fig. 2). However, attempts to show that cAR3 is glycosylated were unsuccessful; treatment of the protein with peptide N-glycosidase F (PNGase F) did not alter its apparent molecular weight on SDS-PAGE (data not shown).

\section{Sequence comparison}

A search of the NBRF protein data bank, using only the sequence of the transmembrane and loop regions, revealed limited identity between the transmembrane re- gions of cAR3 and the following G protein-coupled receptors: turkey $\beta$-adrenergic receptor $(24 \%$ identity over 55 amino acids), pig muscarinic acetylcholine receptor III ( $21 \%$ identity over 132 amino acids), and human green opsin (18\% identity over 120 amino acids). Using the FASTA alignment program (Lipman and Pearson 1985), cAR3 has $56 \%$ and $69 \%$ sequence identity with cAR1 and cAR2, respectively (Klein et al. 1988; Saxe et al. 1991). As shown in Figure 2, the identity between cAR3 and CARl begins at the first transmembrane domain I, extends to the initial portion of the carboxy-terminal domain, and is contiguous with the exception of a singleresidue gap in the first extracellular loop. The sequence identity between the three cARs is highest among transmembrane domains and intracellular loops and is less extensive in the extracellular loops. Little similarity exists between the three receptors before the first transmembrane domain and beyond residue 311 of the carboxyl terminus of cAR3.

Both the amino and carboxyl termini of cAR3 are longer than cAR 1 by 10 and 87 amino acids, respectively.

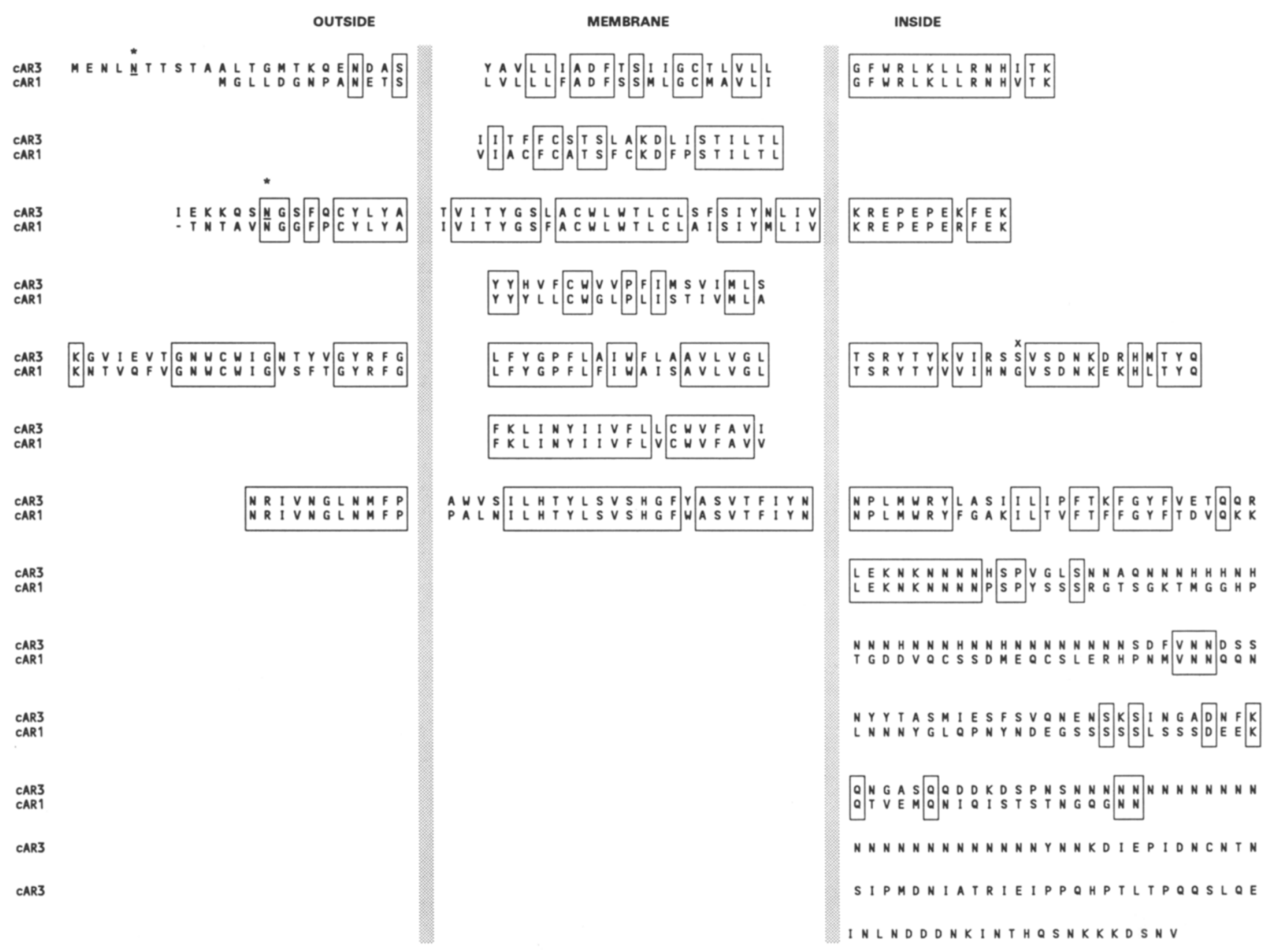

Figure 2. Sequence comparison of cAR 3 and cAR1. The amino acid sequences of cAR3 (top) and cAR 1 (bottom) share $56 \%$ identity when aligned by the DFASTP program (Lipman and Pearson 1985). Two amino-linked glycoslylation sites (*) above asparagine residues and a protein kinase $A$ site $(x)$ are also shown. 
The carboxy-terminal region of cAR3 possesses two regions of asparagine-rich sequence of 27 and 29 amino acids. cDNA clones 4 and 7, which overlapped GR6 at residues $92-368$ and $309-490$, respectively, encompassed the regions of the polyasparagine repeats and confirmed that these stretches were encoded in the protein and were not intron or 3' untranslated sequences. Similar stretches of repeated residues were noted in cAR2 as well (see Saxe et al., this issue).

The cytoplasmic carboxy-terminal domain of cAR3 contains multiple serine and threonine residues, which are the sites of ligand-induced phosphorylation in the $\beta$-adrenergic receptor (O'Dowd et al. 1989), rhodopsin (Kuhn and Dreyer 1972), and cARl (Vaughan and Devreotes 1988; D. Hereld, R. Vaughan, and P. Devreotes, in prep.). An additional 4 serine and 3 threonine residues are present in the intracellular loop between the fifth and sixth putative transmembrane regions. Of these, serine 204, is a protein kinase A consensus phosphorylation site (Fig. 2; Taylor et al. 1990).

\section{Expression of cARs in growth stage cells}

To study the properties of each receptor subtype, fulllength clones of cAR1-cAR3 were ligated into an expression vector, B18, in the sense orientation (Klein et al. 1988; Johnson et al. 1991, 1992). This expression construct uses the actin 15 promoter that is constitutively active during growth and early development (Knecht et al. 1986). The B18 and cAR1 vector were stably transformed into wild-type AX-3 cells, whereas the cAR2 and cAR3 constructs were transformed into a cAR1 null cell line termed $\Delta 208$ (R. Johnson et al. 1993). The $\Delta 208$ cells, which were generated by gene disruption, have negligible cAMP binding during growth and early development (Sun and Devreotes 1991). Transformants were screened and clones that expressed high levels of each subtype were characterized further.

To demonstrate that these receptor clones encode cAMP-binding proteins, each of the cell lines was photoaffinity labeled with $8-\mathrm{N}_{3}\left[{ }^{32} \mathrm{P}\right] \mathrm{cAMP}$ (Fig. 3A). Intact cells were incubated with the photolabel in the absence or presence of excess unlabeled cAMP and irradiated with UV light, and the pellets from detergent extracts were size fractionated. After autoradiography, cells containing the parent vector showed no detectable photolabeling, whereas cells expressing each cAR subtype were specifically labeled. cAR1 and cAR2 migrated at an apparent molecular mass of 40 and $39 \mathrm{kD}$, respectively, and cAR3 appeared as a doublet of 60 and $64 \mathrm{kD}$. Although the number of expressed binding sites was similar in all three cell lines (Johnson et al. 1992), cAR2 photolabeled to a greater extent than either cAR1 or cAR3. The higher molecular mass products present in the cAR2 lanes appeared to be cAR2 aggregates, as they were dependent on plasmid expression. Aggregates of cAR1, which shift in apparent molecular mass with cAMP stimulation, have also been detected (data not shown). The lower molecular mass size forms in the cAR2 lanes are probably degradation products.

When stimulated with cAMP, cAR1 becomes phosphorylated on multiple serines in its carboxy-terminal domain with kinetics that correlate with the adaptation of several ligand-stimulated responses/Vaughan and Devreotes 1988; D. Hereld, R. Vaughan, and P. Devreotes, in prep.). Both cAR2 and cAR3 contain multiple serines and threonines in their carboxy-terminal regions, two of which are conserved among all three subtypes. To determine whether cAR2 and cAR3 become phosphorylated with cAMP stimulation, cell lines expressing cAR1, cAR2, or cAR3 were labeled in vivo with ${ }^{32} \mathrm{P}$-labeled $\mathrm{H}_{3} \mathrm{PO}_{4}$ and stimulated in the absence or presence of $1 \mu \mathrm{M}$ CAMP. Detergent extracts of the cells were prepared, and the pellets were size fractionated. As shown in Figure 3B, ligand-occupied cAR1 shifted in apparent molecular mass from 40 to $43 \mathrm{kD}$ and dramatically increased its level of phosphorylation (Klein et al. 1987). As with cAR1, both CAR2 and CAR3 became highly phosphorylated with cAMP stimulation. In the basal state, cAR2 had little or no detectable phosphorylation and migrated as a 1 to $2-\mathrm{kD}$ smaller size, whereas cAR3 had some basal phosphorylation but did not undergo a detectable shift in apparent molecular mass. Because cARl is phosphory-
Figure 3. Photolabel $(A)$ and in vivo phosphorylation $(B)$ of growing Dictyostelium cells expressing cAR subtypes from plasmid. $(A)$ Growing wild-type cells expressing B18 $(-)$ or cARl (1) or $\Delta 208$ cells expressing cAR2 (2) or cAR3 (3) were photolabeled with $8-\mathrm{N}_{3}\left[{ }^{32} \mathrm{P}\right]$ cAMP in the absence $(-)$ or presence $(+)$ of excess unlabeled cAMP. cAR1, cAR2, and cAR3 migrated as 40,39 , and a doublet of 60 and 64 $\mathrm{kD}$ apparent molecular mass. (B) Growing cells expressing each cAR were labeled in vivo with $\left[{ }^{32} \mathrm{P}\right] \mathrm{H}_{3} \mathrm{PO}_{4}$ for $30 \mathrm{~min}$ and stimulated in the presence or absence of $1 \mu \mathrm{M}$ cAMP for an additional $15 \mathrm{~min}$. The pellets from membrane-extracted cells were then size fractionated. All three receptor subtypes are phosphorylated on multiple residues upon stimulation with ligand and migrate at their expected sizes.

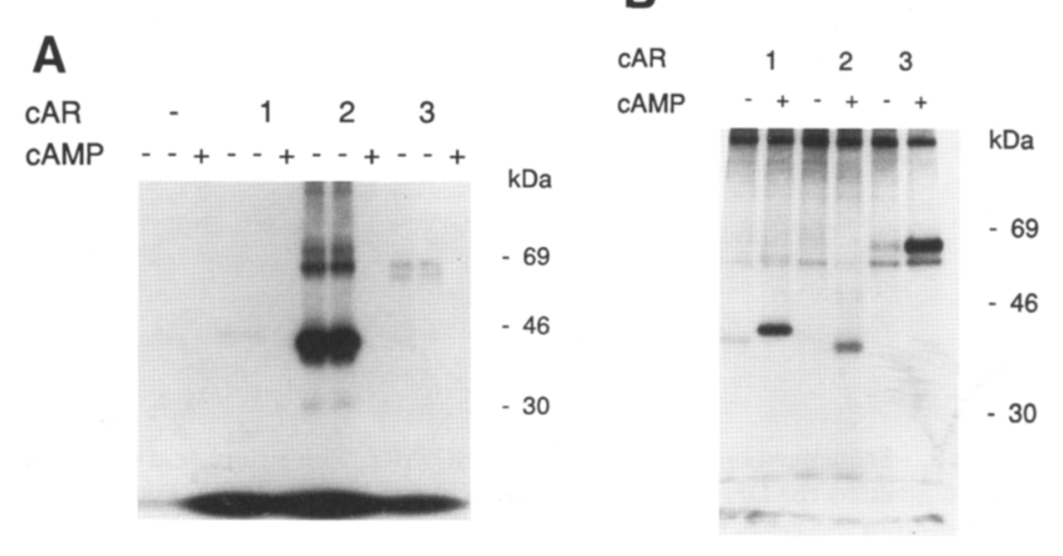


lated at multiple sites and because comparable levels of each receptor are being expressed (cAR1, 3.7 $\times 10^{5}$ sites/ cell; cAR2, $2.1 \times 10^{5}$ sites/cell; cAR3, $6.4 \times 10^{5}$ sites/ cell; Johnson et al. 1992), both cAR2 and cAR3 must also acquire multiple phosphates with stimulation. Amino acid analysis of CAR3 showed that threonine residues were phosphorylated in the basal state, whereas serine residues were targeted upon cAMP stimulation (data not shown).

\section{Developmental and cell-type expression of $c A R 3$}

To examine the developmental regulation of cAR3, wildtype AX-3 cells were developed on agar plates and RNA was isolated every $3 \mathrm{hr}$ until fruiting bodies were formed (Fig. 4A). A RNA blot hybridized with a cAR3 probe revealed a doublet of $\sim 2 \mathrm{~kb}$ that was not present in growing cells. The amount of cAR3 RNA increased to a maximum at the mound stage ( $\sim 9 \mathrm{hr})$, dropped to a lower plateau, and then increased slightly at $15 \mathrm{hr}$.

In contrast to cAR2, which is expressed preferentially in prestalk cells, cAR3 RNA does not appear to be enriched in either prestalk or prespore cells. Migrating pseudoplasmodia were disrupted into single cells and then separated by density in Percoll gradients. RNA was prepared from light and dense fractions, which are enriched in prestalk and prespore cells, respectively (Ratner and Borth 1983), and blotted for hybridization to cAR3 (Fig. 4B). The cAR3 RNA is present in equal amounts in both fractions.

The developmental expression of CAR1 and cAR3 pro-

A

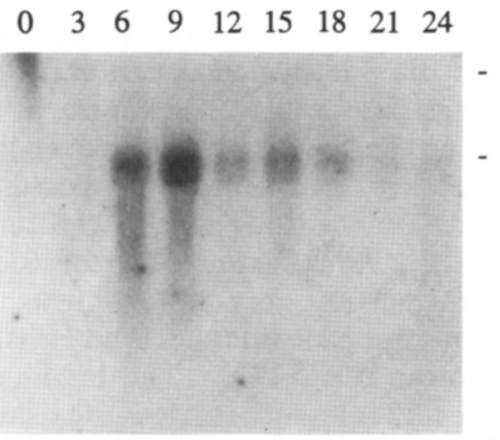

L D

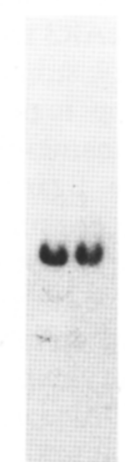

Figure 4. Developmental and cell-type expression of cAR3 RNA. (A) RNA was prepared from wild-type cells at $3 \mathrm{hr}$ intervals throughout development and blotted for hybridization to GR6. A 2-kb doublet of cAR3 RNA was induced during aggregation $(6 \mathrm{hr})$, was maximal at the mound stage $(9 \mathrm{hr})$, and persisted at reduced levels throughout later development. Bars at right indicate the position of RNA ( 2 and $4 \mathrm{~kb})$. (B) RNA was isolated from cells that were separated by density in Percoll gradients and blotted as in $(A)$. Light $(L)$ and dense $(D)$ fractions are enriched in prestalk and prespore cells, respectively.
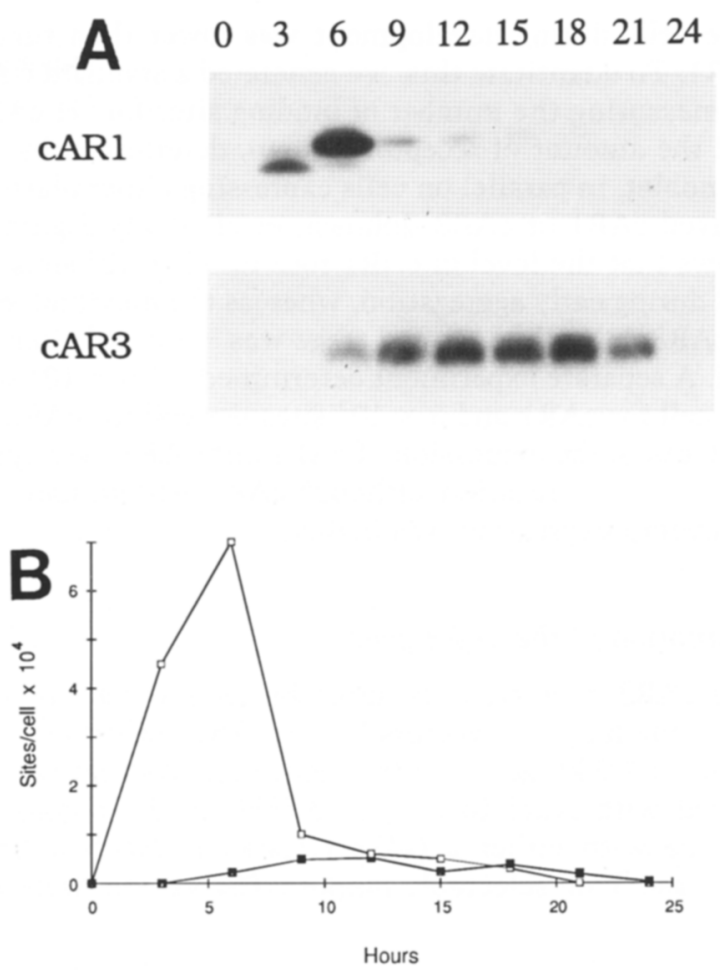

Figure 5. (A) Developmental expression of cAR1 and cAR3 proteins. Protein samples were collected at 3 -hr intervals throughout the development of wild-type cells and immunoblotted with cAR1 or cAR3 antisera. cAR1 migrated at 40 and $43 \mathrm{kD}$ and was expressed mainly during aggregation $(3-6 \mathrm{hr})$. cAR3 appeared as a protein of $\sim 65 \mathrm{kD}$ that was expressed at later stages of development beginning at the mound stage $(9 \mathrm{hr})$. $(B)$ Developmental expression of cAR1- and cAR3-binding sites. cAMP-binding sites of cAR $1(\square)$ and cAR3 ( $\square$ ) were measured during the development of wild-type cells (see Materials and methods). cARl was expressed during early aggregation to $\sim 7 \times 10^{4}$ sites per cell, whereas cAR3 was induced later at 10 fold lower levels $\left(5 \times 10^{3}\right.$ sites per cell).

teins were compared. At 3 -hr intervals throughout development, cells were extracted with SDS sample buffer and prepared for immunoblotting (Fig. 5A). A cAR3 antisera was generated against a synthetic peptide corresponding to the final 20 amino acids of the cAR3 carboxyl terminus (see Fig. 1). cAR1, which migrated at 40 and $43 \mathrm{kD}$, was present in low amounts during growth, peaked earlier during aggregation, and subsided rapidly at later time points (Klein et al. 1987). cAR3 migrated predominantly at an apparent molecular mass of $65 \mathrm{kD}$. Consistent with the time course of its RNA expression, cAR3 was not present in growing cells, was induced at early aggregation $(6 \mathrm{hr})$, and was maximally expressed at the mound stage $(9-12 \mathrm{hr})$. The level of expression then fell briefly, peaked again during the slug stage $(18 \mathrm{hr})$ and declined at culmination. Occasionally, a higher molecular mass form of cAR3 of $67 \mathrm{kD}$ was observed. Separate experiments have shown that the amount or appearance of this larger form did not follow a consistent pattern.

The number of cAR3-binding sites expressed in wild- 
type cells during development was lower than that of cARl. To quantitate this, we generated a standard curve by measuring the number of binding sites for ${ }^{3} \mathrm{H}$-cAMP and the amount of receptor protein, determined by immunoblot, in parallel on cells expressing either plasmidderived cAR1 or cAR3 (Johnson et al. 1992). Figure 5B shows that the level of cAR1 rose to $\sim 7 \times 10^{4}$ sites per cell during early aggregation, whereas the maximal level of cAR3 during the mound stage was $\sim 5 \times 10^{3}$ sites per cell. A separate experiment determined $\sim 2.5 \times 10^{4}$ sites per cell for cAR1 and $5 \times 10^{3}$ sites per cell for cAR3. In both cases, the expression of cAR1 and cAR3 overlapped during late aggregation, although cAR1 predominated, as its overall expression was higher.

\section{Disruption of the cAR3 gene}

The cAR3 gene was disrupted by recombination with two gene-targeting vectors (Fig. 6). The constructs contained a $2.9-\mathrm{kb}$ genomic fragment of cAR3 that was digested with $N d e$ I to replace $0.73 \mathrm{~kb}$ of the coding sequence with either a G418 resistance (Neo) or UMP synthase (Ura) selectable marker. The vectors were lin-
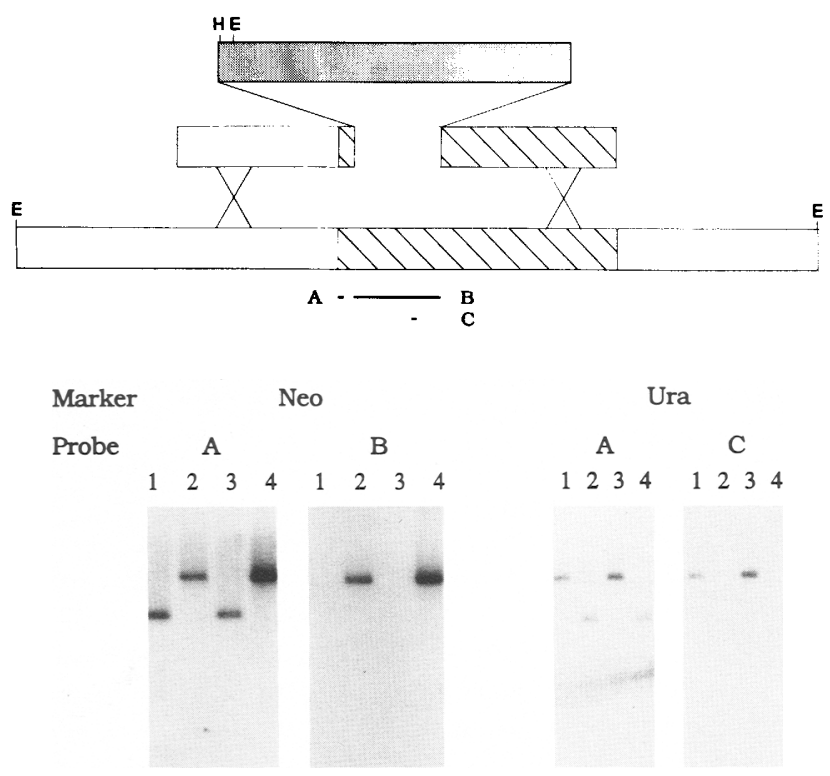

Figure 6. cAR3 gene disruption construct and genomic analysis of transformants. (Top) Diagram of the disruption construct containing either a $2.2-\mathrm{kb}$ neomycin resistance marker or a 3.7$\mathrm{kb}$ UMP synthase gene (shaded region), flanked by $1 \mathrm{~kb}$ of $5^{\prime}$ noncoding sequence (unshaded regions) and $1 \mathrm{~kb}$ cAR3-coding sequence (hatched region). Genomic DNA was prepared from transformants, digested with EcoRI (Neo) or EcoRI-HindIII (Ura) and blotted for hybridization with several cAR3 probes. Four independent clones from each transformation are shown. Probe A is a 32-bp oligomer corresponding to the amino-terminal sequence of cAR3, probe B is the cAR3 NdeI fragment, and probe $\mathrm{C}$ is another oligomer that is absent in the disruption constructs, as indicated. In each case (Neo or Ura), the blots on the left, which had been hybridized with probe A, were stripped and rehybridized with probe $\mathrm{B}$ or $\mathrm{C}$. earized and transformed into Dictyostelium cells, and clones were selected. Genomic DNA was prepared from transformants, digested with EcoRI (Neo) or EcoRIHindIII (Ura), and blotted for hybridization with several cAR3 probes. In Figure 6, four independent clones from each transformation are shown. Probe A, a 32-bp oligomer corresponding to the amino-terminal sequence of cAR3, detects two size bands, a 5-kb band representing the intact cAR3 gene and an $\sim 2.5-\mathrm{kb}$ band, indicating a double crossover event with the vector that introduced a new EcoRI or HindIII site. To confirm this result, the blots were stripped and then probed with either the cAR3 NdeI fragment (probe B) or an oligomer (probe C) that is absent in the disruption construct. The clones that had the smaller band did not hybridize with the $0.7-\mathrm{kb}$ fragment or oligomer and confirmed that this cAR3 coding sequence was absent from its genome. These transformants were characterized further.

The car $3^{-}$(neo) cells lacked cAR3 protein but expressed normal levels of cAR1 protein with the proper developmental expression (data not shown). Several independent "random" integrants and car3- clones (i.e., lanes 1-4 in Fig. 6) have been examined in parallel under our standard developmental conditions. No obvious differences in the timing of development or the morphological features of the aggregates have been observed.

\section{Discussion}

We report the identification of a new cAMP receptor subtype, cAR3, that is a member of the cAMP receptor family, which currently includes three other subtypes, cAR1 (Klein et al. 1988), cAR2 (Saxe et al., this issue), and cAR4 (J. Louis, G. Ginsburg, and A. Kimmel, in prep.). Each subtype has a distinct pattern of expression during development, which suggests that it mediates a specific role in the program.

cAR3 shares $\sim 65 \%$ amino acid identity with the other CAR subtypes within the putative transmembrane and loop regions. The high degree of conservation in the transmembrane domains suggests that they may enclose the ligand-binding pocket in a manner proposed for rhodopsin (Findlay and Pappin 1986) and the $\beta$-adrenergic receptor (Dixon et al. 1987). Pharmacological studies have suggested that the adenine ring of cAMP rests in a hydrophobic pocket in three cAR subtypes (Van Haastert and Kien 1983; Johnson et al. 1992). The binding of cAMP derivatives to CAR2 is less sensitive to the relative changes in hydrophobicity when compared with CAR 1 and cAR3. The photolabeling reaction appears more efficient for CAR2 than cAR1 or cAR3 as saturating concentrations of photolabel were used. Although the affinity of cAR2 under the conditions of the photolabeling reaction is similar to the other subtypes, it may bind $8-\mathrm{N}_{3}\left[{ }^{32} \mathrm{P}\right] \mathrm{cAMP}$ differently so that the azido group reacts more productively.

The cytoplasmic carboxy-terminal domains of all three subtypes are rich in serine and threonine residues. cAR1 contains 18 serines grouped into four clusters in 
its carboxyl terminus, and these residues comprise the sites for ligand-induced phosphorylation (D. Hereld, R. Vaughan, and P. Devreotes, in prep.). cAR2 and cAR3 contain 9 and 26 serine and threonine residues, respectively, in their carboxy terminal regions, which are more evenly distributed. Serines 310 and 315 of cAR3 are conserved in their sequence position between the three cARs. In addition, cAR 2 and cAR 3 contain a conserved protein kinase A phosphorylation site in the third cytoplasmic loop region.

All three cAR subtypes become phosphorylated in response to cAMP. Because cAR2 and cAR3 are expressed in the $\Delta 208$ cells that lack cAR1, the receptor kinases cannot be acting on these subtypes indirectly by activation by cAR1. Instead, the receptor kinases appear to be activated upon ligand occupation of each receptor. Because of the high degree of sequence identity between the three cARs, it seems likely that a single protein kinase phosphorylates the receptors. In support of this, plasmid-expressed cAR1 and cAR3 can be phosphorylated equally well during early aggregation (Johnson et al. 1991) and the mound stage, respectively (data not shown), suggesting that receptor kinases are present throughout development. The kinetics of phosphorylation differ between the cARs. cARl has a half-time of $\sim 45 \mathrm{sec}$ (Vaughan and Devreotes 1988), whereas the halftimes of CAR2 and cAR3 are slower (data not shown).

The proposed intracellular loops of the three cARs are highly conserved and are rich in charged residues. Structure and function experiments on rhodopsin and the $\beta$-adrenergic receptor have shown the cytoplasmic regions nearest the transmembrane domains to be important in receptor-G protein coupling (Strader et al. 1987; O'Dowd et al. 1988; Weiss et al. 1988). Chimeras between the $\alpha_{2}$ - and $\beta_{2}$-adrenergic receptors demonstrate that the loop between transmembrane domains $\mathrm{V}$ and VI is the most important region for coupling to $G_{s}$ (Bouvier et al. 1988). Other studies have indicated that in addition to the V/VI loop, the III/IV loop is needed to switch G protein specificity (Wong et al. 1990). Because the loop regions are highly conserved between the cARs, it seems likely that these receptors couple to the same $G$ protein or class of $G$ proteins. The expression of any of the three cAR subtypes in the car1- cells can restore cAMP-induced $\mathrm{Ca}^{+2}$ influxes and cAMP-induced phosphorylation of the $G_{\alpha} 2$ subunit, responses that are absent in the parent cells (Johnson et al. 1993; J. Milne and P.N. Devreotes 1993). However, neither cAR2 nor cAR3 was able to completely rescue the aggregation minus phenotype of the car $1^{-}$cells.

The protein kinase A phosphorylation site in the third cytoplasmic loop of cAR2 and cAR3 may be functionally significant. In the $\beta$-adrenergic receptor, a peptide that is derived from this loop and contains such a consensus site can stimulate adenylyl cyclase in vitro, and this activity is abolished upon phosphorylation of the peptide by protein kinase A (Okamoto et al. 1991). In Dictyostelium, overproduction of the regulatory subunit of protein kinase A blocks development before the mound stage (Simon et al. 1989). Possibly, protein kinase A acts on cAR2 or cAR3 to block an inhibitory response that allows differentiation to begin.

cAR3 protein appeared as a doublet when expressed either from plasmid during growth or endogenously during development and it migrated at a larger size than predicted from its amino acid sequence. When protein extracts from the $\Delta 208 / \mathrm{cAR} 3$ cells were immunoblotted with specific antiserum or when intact cells were photolabeled with $8-\mathrm{N}_{3}\left[{ }^{32} \mathrm{P}\right] \mathrm{cAMP}, \mathrm{cAR} 3$ migrated as a doublet of $57-60$ and $62-64 \mathrm{kD}$. The doublet may have arisen from a number of possible causes: Translational initiation may have occurred at both Met 1 and 15. Protein degradation may have occurred at the carboxyl terminus as both forms of cAR3 were photolabeled evenly while the antiserum generated against the carboxy-terminal 20 amino acids predominantly recognized the larger form. In addition, the asparagine-rich regions in the carboxyl terminus may have caused the anomalous migration.

The maximal number of cAR3 sites measured in mound-stage wild-type cells was $\sim 5 \times 10^{3}$ sites per cell. In contrast, cAMP-binding sites present during early aggregation, which are mainly comprised of cARl (Klein et al. 1987), rise to $5 \times 10^{4}$ to $10 \times 10^{4}$ sites per cell (Green and Newell 1975; Klein and Juliani 1977; Van Haastert 1985). During late aggregation (6-9 hr), both cARl and cAR3 were present. We do not know whether cAR3 is expressed in all cells at low levels or in a subset of cells at higher levels. However, Percoll gradient fractionation of slug stage cells showed that both cAR1 and cAR3 RNA distribute similarly in prestalk and prespore cells (Fig. 3B; Saxe et al. 1991). Immunofluorescence staining of developed individual cells or multicellular structures with the cAR3 antiserum should distinguish between these two possibilities.

The lack of an obvious phenotype in the car $3^{-}$cells is intriguing. The presence of a family of highly related surface receptors suggests there is redundancy built into cell-cell signaling strategies in development. cAR3 appears after CAR1 and before cAR2, but its time course of expression overlaps with each. Furthermore, the affinity of CAR3 for CAMP is intermediate between that of CAR1 and cAR2. These observations suggest that CAR1 or cAR2, or both, may substitute for CAR3 to bring about apparently normal development under our standard conditions. We are currently examining the car $3^{-}$cells under a wider variety of developmental conditions that may reveal a specific requirement for cAR3.

\section{Materials and methods}

\section{Cell culture and development}

AX-3 cells were grown in HL-5 media (Watts and Ashworth 1970) and vector-transformed cells were grown in HL-5 media with $20 \mu \mathrm{g} / \mathrm{ml}$ of neomycin (G418). All cells were harvested during late log phase growth and washed once in $10 \mathrm{mM} \mathrm{PO}_{4}$ buffer (pH 6.5) containing $2 \mathrm{mM} \mathrm{MgSO}_{4}$ and $0.2 \mathrm{mM} \mathrm{CaCl}_{2}$. Cells were developed on $1.5 \%$ agarose plates at $5 \times 10^{7}$ cells per 10 $\mathrm{cm}$ petri dish (Devreotes et al. 1987). 


\section{Isolation and sequencing of clones}

Hybridization conditions for all blots and lifts were as follows. Nitrocellulose filters were hybridized in $50 \%$ formamide, $1 \mathrm{M}$ $\mathrm{NaCl}, 1 \%$ SDS, and $10 \%$ dextran sulfate overnight at $42^{\circ} \mathrm{C}$ and washed twice with $2 \times \mathrm{SSC}, 1 \%$ SDS at $60-65^{\circ} \mathrm{C}$, for $30 \mathrm{~min}$ each.

For library screening, $\sim 10^{5}$ clones of a partial Sau3AI Dictyostelium genomic library (PAT plasmid; library provided by R. Firtel, University of California, San Diego) were probed with ${ }^{32} \mathrm{P}$ random-primed (Feinberg and Vogelstein 1983) 6B, a full-length cDNA of cAR1 (Klein et al. 1988). A $1.7-\mathrm{kb}$ clone, GR6, was isolated and contained the entire coding region of cAR3 (Fig. 1). Four cAR3 cDNAs were obtained by screening $5 \times 10^{5}$ clones of a Dictyostelium $\lambda$ gt11 library (Klein et al. 1988) using ${ }^{32} \mathrm{P}-\mathrm{la}$ beled random-primed GR6 as a probe. Three cDNAs /clones 1, 4, and 5) were subcloned into the EcoRI site of Bluescript (KS+, Stratagene), whereas $0.5-\mathrm{kb}$ of the fourth (clone 7) was amplified by PCR using a $5^{\prime}$ cAR3 primer $15^{\prime}$-CCGAATTCCATTCACCAGTTGGGTTATC- $3^{\prime} \mid$ and a $3^{\prime} \lambda$ primer that flanked the cloning site. Double-stranded sequencing was performed by dideoxy-nucleotide chain termination (Sanger et al. 1977). Two primers (the above-mentioned and 5'-GGTTCATTGGCATGTTGGC-3') were used for sequencing.

\section{Vector construction and transformation}

To create the cAR3 disruption construct, a modified Bluescript vector (Stratagene), pSL-4, was used. This construct has a 24-bp palindromic oligo, which contains stop codons (TAG) in all three reading frames and a $B g I I I$ site, ligated into the EcoRV site. pSL-4 was digested with Sall, filled in, and ligated to remove its AccI site. Full-length cAR3 was obtained by digesting GR6 with $X b a I$ and SmaI. This insert was filled in, had BamHI linkers added, and was cloned into the BamHI site of pSL-4. pSL-4/ cAR3 was digested with $\mathrm{XbaI}$, filled in and digested with $A c c \mathrm{I}$ to remove the 5 '-coding region of cAR3. This was replaced by the AccI-EcoRV fragment from 5PcAR3 (a 2-kb genomic fragment of cAR3 cloned into the EcoRI site of Bluescript), which contained $1.8 \mathrm{~kb}$ of $5^{\prime}$ of the cAR3 AccI site. This vector, 5cAR3, was digested with NdeI to remove $\sim 0.5 \mathrm{~kb}$ of cAR3-coding sequence. Markers for G418 resistance (BamHI-BglII fragment from NeolDXTBR, A15TX; Cohen et al. 1986) containing the G418 ${ }^{R}$ cassette (NPT1 gene flanked by the actin 15 promoter and terminator) and for uracil prototrophy (ClaI fragment of p3B1; Kalpaxis et al. 1991) were blunted and cloned into NdeI site of 5 cAR3 to create 5 cAR3neo and 5 cAR3ura vectors, respectively. The constructs were linearized with EcoRI and transformed into Dictyostelium (uracil auxotroph; gift of W. Loomis, University of California, San Diego) by electroporation as described (Sun and Devreotes 1991). Transformant clones were selected with $10 \mu \mathrm{g} / \mathrm{ml}$ of G418 and $0.2 \mathrm{mM}$ uracil (Neo) or FM minimal medium (Franke and Kessin 1977) (Ura). The B18, cAR1, D208/cAR2, and D208/cAR3 cells have been described previously (Johnson et al. 1991, 1992).

\section{DNA and RNA isolation and analysis}

Genomic DNA was isolated by removing cells from confluent 10-cm Petri dishes, pelleting and resuspending in $0.5 \mathrm{ml}$ buffer containing $0.32 \mathrm{M}$ sucrose, $5 \mathrm{~mm} \mathrm{MgCl}, 1 \%$ Triton $\mathrm{X}-100$, and $10 \mathrm{~mm}$ Tris $(\mathrm{pH} 7.5)$. After pelleting for $10 \mathrm{~min}$ at $14 \mathrm{~K}$ nuclei were resuspended in $0.2 \mathrm{ml}$ of $10 \mathrm{~mm}$ EDTA in $10 \mathrm{~mm}$ Tris $(\mathrm{pH}$ 7.5) to which $0.2 \mathrm{ml}$ of $0.1 \%$ SDS in $10 \mathrm{~mm}$ Tris (pH 7.5) was added. After gentle mixing, $1 \mathrm{mg} / \mathrm{ml}$ final concentration RNase A was added and the DNA was incubated at $65^{\circ} \mathrm{C}$ for $30 \mathrm{~min}$. Proteinase $\mathrm{K}$ (final concentration, $2 \mathrm{mg} / \mathrm{ml}$ ) was added and the incubation repeated for $45 \mathrm{~min}$. The DNA was extracted and precipitated as described (Sambrook et al. 1989). DNA (5 $\mu \mathrm{g}$ ) was restriction digested with EcoRI (Neo) or EcoRI-HindIII (Ura), separated on $0.8 \%$ agarose gels, and blotted as described (Sambrook et al. 1989). Two oligonucleotides, (5'-ATGGAAAATTTAAATACAACAAGTACGGAGC-3' and 5'-CCCGTCACCTCTATAACACCC $-3^{\prime}$ ), corresponding to nucleotides 1-32 and 453-473 of the cAR3-coding sequence, respectively, and the 0.73-kb NdeI fragment of cAR3 were used as probes (Fig. 6).

Total RNA was isolated from AX-3 cells during development as described (Klein et al. 1988). In brief, $5 \times 10^{7}$ cells were solubilized in $4 \mathrm{ml}$ of $6 \mathrm{M}$ guanidine- $\mathrm{HCl}$, incubated at $65^{\circ} \mathrm{C}$ for 5 $\mathrm{min}$, and precipitated with one-half volume of ethanol at $-20^{\circ} \mathrm{C}$ for $2 \mathrm{hr}$. After pelleting RNA for $30 \mathrm{~min}$ at $5 \mathrm{~K}$, the procedure was repeated two more times using half the starting volumes with the final pellet resuspended in $0.4 \mathrm{ml}$ of water and precipitated. The RNA was pelleted, washed with $80 \% \mathrm{EtOH}$, and resuspended in $50 \mu \mathrm{l}$ of TE. Five micrograms of each RNA sample was size fractionated on an agarose gel containing formaldehyde, blotted as described (Sambrook et al. 1989), then hybridized with GR6.

Prestalk and prespore RNA were isolated by disrupting migrating pseudoplasmodia and separating cells by density in Percoll gradients as described (Ratner and Borth 1983).

\section{Preparation of antigen and immunization}

The peptide $\mathrm{NH}_{2}$-CNDDDNKINTHQSNKKKDSNV- $\mathrm{CO}_{2} \mathrm{H}$, corresponding to the final 20 amino acids of cAR3, with a cysteine added at the amino terminus for cross-linking purposes, was synthesized. The peptide was attached to keyhold limpet cyanin (KLH) as described (Green et al. 1982) and injected subcutaneously into a rabbit. High titer serum was obtained after a second boost 4 weeks later and used routinely at $1: 1000$ or $1: 2000$ dilution.

\section{Estimation of receptor abundance during development}

The number of cAR1 and CAR3 binding sites was measured throughout the development of wild-type cells in the following manner. Total receptor sites per cell were determined by Scatchard analysis of transformed cells expressing plasmid-derived cARl or cAR3 (cAR1 and $\Delta 208 /$ cAR3 cells, respectively; Johnson et al. 1992). In addition, whole-cell extracts were prepared at $5 \times 10^{7}$ cells $/ \mathrm{ml}$, and a titration series of twofold dilutions (to $1: 1024$ ) was made. From wild-type cells, whole-cell extracts were prepared every $3 \mathrm{hr}$ throughout development on agarose plates at $5 \times 10^{7} \mathrm{cells} / \mathrm{ml}$. Protein samples of the time course and the cAR 1 or cAR 3 titration series were separated by SDS-PAGE. These gels were transferred together, immunoblotted together using either CAR1 or cAR3 antisera, and exposed to the same film. After autoradiography, the receptor bands from the titration series were scanned by a densitometer to correlate the intensity of the protein band with the number of receptor sites per cell to generate a standard curve. The developmental time course of each receptor was then compared with its respective standard curve to determine receptor number. This experiment was performed twice with similar results.

\section{In vivo phosphorylation}

Growing cells were prepared for in vivo labeling as described (Vaughan and Devreotes 1988) and resuspended at $10^{8} / \mathrm{ml}$. Two milliliters of cells were shaken at $\sim 150 \mathrm{rpm}$ and incubated with $0.3 \mathrm{mCi} / \mathrm{ml}$ of ${ }^{32} \mathrm{P}$-labeled $\mathrm{H}_{3} \mathrm{PO}_{4}$ and $5 \mathrm{~mm}$ caffeine for $30 \mathrm{~min}$ at room temperature. One milliliter of cells was then trans- 
ferred to a second cup containing $1 \mu \mathrm{M}$ cAMP and $10 \mathrm{mM}$ DTT for $15 \mathrm{~min}$. Extracts were prepared from $0.5 \mathrm{ml}$ cells and separated as described (Johnson et al. 1992).

\section{Other assays}

Intact cells were photoaffinity labeled with $100 \mathrm{nM} 8-\mathrm{N}_{3}\left[{ }^{32} \mathrm{P}\right]-$ cAMP using a modification of the previously described procedure (Devreotes et al. 1987). After 3 min of UV radiation, cells were extracted in a lysis buffer containing $1.5 \%$ CHAPS (Klein et al. 1985) and separated as described (Johnson et al. 1992). Whole-cell extracts were immunoblotted as described (Klein et al. 1987). To detect cAR1, a polyclonal antiserum generated against the purified receptor, $\mathrm{R} 4$, was used at $1: 1000$ dilution (Klein et al. 1987).

\section{Acknowledgments}

We thank Dr. R. Firtel for providing the PAT library, Dr. T. Dingermann for giving the $3 \mathrm{~B} 1$ plasmid, $\mathrm{S}$. Lee for making the pSL4 vector, and J. Borleis for excellent technical assistance. We are grateful to $\mathrm{C}$. Montell for critical reading of the manuscript. This work was supported by a grant from the National Institutes of Health (GM34933) to P.N.D.

The publication costs of this article were defrayed in part by payment of page charges. This article must therefore be hereby marked "advertisement" in accordance with 18 USC section 1734 solely to indicate this fact.

\section{References}

Bouvier, M., W.P. Hausdorff, A. DeBlasi, B.F. O'Dowd, B.K. Koblika, M.G. Caron, and R.J. Lefkowitz. 1988. Removal of phosphorylation sites from the $\beta_{2}$-adrenergic receptor delays onset of agonist-promoted desensitization. Nature 333: 370373.

Cohen, S.M., D. Knecht, H.F. Lodish, and W.F. Loomis. 1986. DNA sequences required for expression of a Dictyostelium actin gene. EMBO J. 5: 3361-3366.

Devreotes, P.N. 1982. Chemotaxis. In The development of Dictyostelium discoideum (ed. W.F. Loomis), pp.117-168. Academic Press, New York.

Devreotes, P., D. Fontana, P. Klein, J. Sherring, and A. Theibert 1987. Transmembrane signalling in Dictyostelium. Methods Cell Biol. 28: 299-331.

Dixon, R.A.F., I.S. Sigal, E. Rands, R.B. Register, M.R. Candelore, A.D. Blake, and C.D. Strader. 1987. Ligand binding to the $\beta$-adrenergic receptor involves its rhodopsin-like core. Nature 326: 73-77.

Dohlman, H.G., J. Thorner, M.G. Caron, and R.J. Lefkowitz. 1991. Model systems for the study of seven-transmembranesegment receptors. Annu. Rev. Biochem. 60: 653-688.

Feinberg, A.P. and B. Vogelstein. 1983. A technique for radiolabeling DNA restriction endonuclease fragments to high specific activity. Anal. Biochem. 132: 6-13.

Findlay, J.B.C. and D.J.C. Pappin. 1986. The opsin family of proteins. Biochem. J. 238: 625-642.

Franke, J. and R. Kessin. 1977. A defined medium for axenic strains of Dictyostelium discoideum. Proc. Natl. Acad. Sci. 74: 2157-2161.

Green, A.A. and P.C. Newell. 1975. Evidence for the existence of two types of cAMP-binding sites in aggregating cells of Dictyostelium discoideum. Cell 6: 129-136.

Green, N., H. Alexander, A. Olson, S. Alexander, T.M. Shinnick, J.G. Sutcliffe, and R.A. Lerner. 1982. Immunogenic structure of the influenza virus hemagglutinin. Cell 28: $477-487$.

Johnson, R.L., R. Gunderson, D. Hereld, G.S. Pitt, S. Tugendreich, C.L. Saxe, A.R. Kimmel, and P.N. Devreotes. 1993. G-protein-linked signaling pathways mediate development in Dictyostelium. Cold Spring Harbor Symp. Quant. Biol. 57: (in press).

Hargrave, P.A. 1986. In The retina (ed. R. Adler and D. Farber), pp. 207-237. Academic Press, New York.

Hubbard, S.C. and R.J. Ivatt. 1981. Synthesis and processing of asparagine-linked oligosaccharides. Annu. Rev. Biochem. 50: $555-583$.

Johnson, R.L., R.A. Vaughan, M.J. Caterina, P.J.M. Van Haastert, and P.N. Devreotes. 1991. Overexpression of the cAMP receptor 1 in growing Dictyostelium cells. Biochemistry 30: 6982-6986.

Johnson, R.L., P.J.M. Van Haastert, A.R. Kimmel, C.L. Saxe, B. Jastorff, and P.N. Devreotes. 1992. The cyclic nucleotide specificity of three cAMP receptors in Dictyostelium. J. Biol. Chem. 267: 4600-4607.

Kalpaxis, D., I. Zundorf, H. Werner, N. Reindl, E. Boy-Marcotle, M. Jaquet, and T. Dingerman. 1991. Positive selection for Dictyostelium discoideum mutants lacking UMP synthase activity based on resistance to 5-fluoroorotic acid. Mol. Gen. Genet. 225: 492-500.

Klein, C. and M.H. Juliani. 1977. cAMP-induced change in cAMP-binding sites on $D$. discoideum amoebas. Cell 10: 329-335.

Klein, P., A. Theibert, D. Fontana, and P.N. Devreotes. 1985. Identification and cAMP-induced modification of the cAMP receptor in Dictyostelium discoideum. I. Biol. Chem. 260: 1757-1764.

Klein, P., R. Vaughan, J. Borleis, and P. Devreotes. 1987. The surface cyclic AMP receptor in Dictyostelium. J. Biol. Chem. 262: 358-364.

Klein, P., T.J. Sun, C.L. Saxe, A.R. Kimmel, R.L. Johnson, and P.N. Devreotes. 1988. A chemoattractant receptor controls development in Dictyostelium discoideum. Science 241: 1467-1472.

Knecht, D.A., S.M. Cohen, W.F. Loomis, and H.F. Lodish. 1986. Developmental regulation of Dictyostelium discoideum actin gene fusions carried on low-copy and high-copy transformation vectors. Mol. Cell. Biol. 6: 3973-3983.

Kuhn, H. and W.J. Dreyer. 1972. Light dependent phosphorylation of rhodopsin by ATP. FEBS Lett. 20: 1-6.

Kyte, J. and R.F. Doolittle. 1982. A simple method for displaying the hydropathic character of a protein. J. Mol. Biol. 157: 105132.

Lipman, D.J. and W.R. Pearson. 1985. Rapid and sensitive protein similarity searches. Science 227: 1435-1441.

Milne, J. and P. Devreotes. 1993. The surface cAMP receptors CAR1, CAR2, and CAR3, promote $\mathrm{Ca}^{+2}$ influx in Dictyostelium by a G $\alpha 2$-independent mechanism. Mol. Biol. Cell (in press|.

O'Dowd, B.F., M. Hnatowich, J.W. Regan, W.M. Leader, M.G. Caron, and R.J. Lefkowitz. 1988. Site-directed mutagenesis of the cytoplasmic domains of the human $\beta_{2}$-adrenergic receptor. J. Biol. Chem. 263: 15985-15992.

O'Dowd, B. F., R.J. Lefkowitz, and M.G. Caron. 1989. Structure of the adrenergic and related receptors. Annu. Rev. Neurosci. 12: 67-83.

Okamoto, T., Y. Murayama, Y. Hayashi, M. Inagaki, E. Ogata, and I. Nishimoto. 1991. Identification of a $\mathrm{G}_{\mathrm{s}}$ activator region of the $\beta_{2}$-adrenergic receptor that is autoregulated via protein kinase A-dependent phosphorylation. Cell 67: 723730 . 
Pupillo, M., R. Install, G.S. Pitt, and P.N. Devreotes. 1992. Multiple cyclic AMP receptors are linked to adenylyl cyclase in Dictyostelium. Mol. Biol. Cell 3: 1229-1234.

Ratner, D. and W. Borth. 1983. Comparison of differentiating Dictyostelium discoideum cell types separated by an improved method of density gradient centrifugation. Exp. Cell Res. 143: 1-13.

Sambrook, J., E.F. Fritsch, and T. Maniatis. 1989. In Molecular cloning: A laboratory manual 7.43-7.44. Cold Spring Harbor Laboratory Press, Cold Spring Harbor, New York.

Sanger, F., S. Nicklen, and A.R. Coulson. 1977. DNA sequencing with chain-terminating inhibitors. Proc. Natl. Acad. Sci. 74: 5463-5467.

Saxe, C.L., R.L. Johnson, P.N. Devreotes, and A.R. Kimmel. 1991. Expression of a cAMP receptor gene of Dictyostelium and evidence for a multigene family. Genes \& Dev. 5: 1-8.

Schaap, P., and W. Spek. 1984. Cyclic AMP binding to the cell surface during development of Dictyostelium discoideum. Differentiation 27: 83-87.

Schaap, P. and R. Van Driel. 1985. Induction of post-aggregative differentiation in Dictyostelium discoideum by cAMP. Exp. Cell. Res. 159: 388-398.

Schenk, P.W., S. Van Es, F. Kesbeke, and B.E. Snaar-Jagalska. 1991. Involvement of cyclic AMP cell-surface receptors and G-proteins in signal transduction during slug migration of Dictyostelium discoideum. Dev. Biol. 145: 110-118.

Simon, M., D. Driscoll, R. Mutzel, D. Part, J. Williams, and M. Veron. 1989. Overproduction of the regulatory subunit of the cAMP-dependent protein kinase blocks the differentiation of Dictyostelium discoideum. EMBO J. 8: 2039-2043.

Strader, C.D., R.A.F. Dixon, A.H. Cheung, M.R. Candelore, A.D. Blake, and I.S. Sigal. 1987. Mutations that uncouple the $\beta$-adrenergic receptor from $G_{s}$ and increase agonist affinity. I. Biol. Chem. 262: 16439-16443.

Sun, T.J. and P.N. Devreotes. 1991. Gene targeting of the aggregation stage cAMP receptor cARl in Dictyostelium. Genes \& Dev. 5: 572-582.

Taylor, S.S., J.A. Buechler, and W. Yonemoto. 1990. cAMP-dependent protein kinase: Framework for a diverse family of regulatory enzymes. Annu. Rev. Biochem. 59: 971-1005.

Van Haastert, P.J.M. 1985. The modulation of cell-surface cAMP receptors from Dictyostelium discoideum by ammonium sulfate. Biochim. Biophs. Acta 845: 254-260.

Van Haastert, P.J.M. and E. Kien. 1983. Binding of cAMP derivatives to Dictyostelium discoideum cells. Activation mechanism of the cell-surface cAMP receptor. I. Biol. Chem. 258: $9636-9642$.

Vaughan, R.A. and P.N. Devreotes. 1988. Ligand-induced phosphorylation of the CAMP receptor from Dictyostelium discoideum. J. Biol. Chem. 263: 14538-14543.

Watts, D. and J. Ashworth. 1970. Growth of myxamoebae of the cellular slime mould Dictyostelium discoideum in axenic culture. Biochem. J. 119: 171-174.

Weiss, E.R., D.J. Kelleher, and G.L. Johnson. 1988. Mapping sites of interaction between rhodopsin and transducin using rhodopsin antipeptide antibodies. J. Biol. Chem. 263: 61506154.

Wong, S.K.-F., E.M. Parker, and E.M. Ross. 1990. Chimeric muscarinic cholinergic: $\beta$-adrenergic receptors that activate $G_{s}$ in response to muscarinic agonists. $J$. Biol. Chem. 265: 6219-6224. 


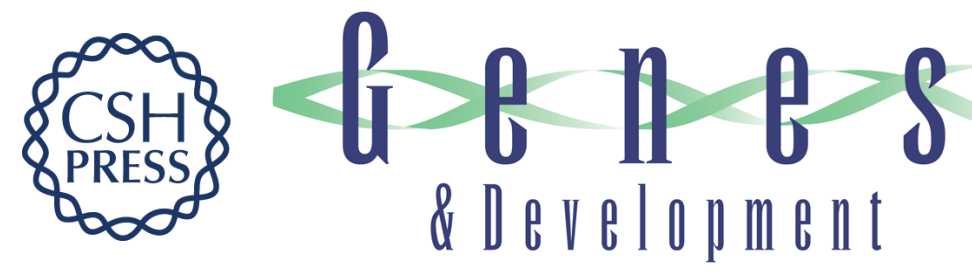

\title{
Identification and targeted gene disruption of cAR3, a cAMP receptor subtype expressed during multicellular stages of Dictyostelium development.
}

\author{
R L Johnson, C L Saxe, R Gollop, et al.
}

Genes Dev. 1993, 7:

Access the most recent version at doi:10.1101/gad.7.2.273

References This article cites 42 articles, 18 of which can be accessed free at: http://genesdev.cshlp.org/content/7/2/273.full.html\#ref-list-1

\section{License}

Email Alerting Service

Receive free email alerts when new articles cite this article - sign up in the box at the top right corner of the article or click here.

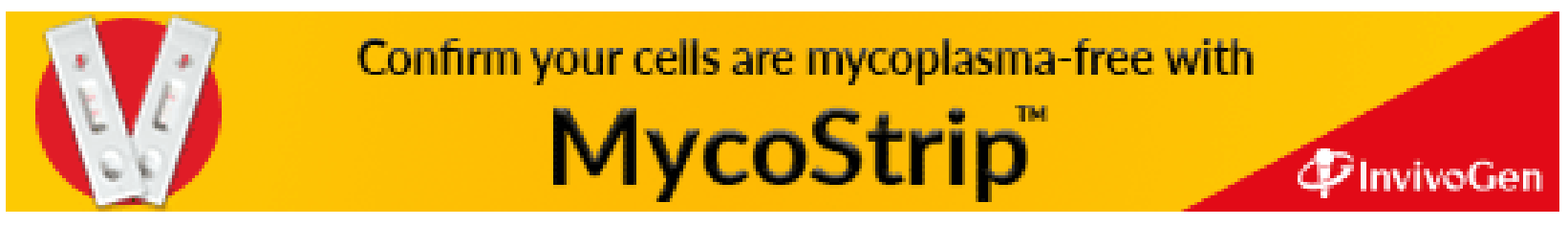

